\title{
Measurement and Correlates of Child Mortality in Yemen
}

\author{
Michele Romanello \\ Universidade Federal de Santa Catarina (UFSC), Florianópolis, Brazil \\ Email: romanello.michele@gmail.com
}

How to cite this paper: Romanello, M. (2018) Measurement and Correlates of Child Mortality in Yemen. Open Access Library Journal, 5: e4905.

https://doi.org/10.4236/oalib.1104905

Received: September 14, 2018

Accepted: October 28, 2018

Published: October 31, 2018

Copyright $\odot 2018$ by author and Open Access Library Inc.

This work is licensed under the Creative Commons Attribution International License (CC BY 4.0).

http://creativecommons.org/licenses/by/4.0/

\begin{abstract}
Child mortality is one of the most important indicators of a country's general medical and health quality, and subsequently, the country's level of socio-economic development. Yemen is one of the poorest countries in the Middle East and North Africa region and has a low Human Development Index (HDI), presenting high rates of child mortality. The objective of this paper is to calculate the rate of infant mortality and child mortality in Yemen and put into evidence some characteristics of households that may influence the rate of child mortality. The database that is used is the Yemen National Social Protection and Monitoring Survey (NSPMS). The Brass indirect method was used for calculating infant and child mortality rates, while Poisson regression was utilized for putting into evidence covariates that may affect mortality. According to the results of Brass indirect analysis, infant and child mortality rates are elevated in Yemen. Poisson regression puts into evidence the importance of mother education, quantity of water available, household economic situation and electricity in household in reducing child mortality. Yemen needs to increase the access to schools of population, particularly of girls, and improve the infrastructure of the country, mainly water and electricity supply, with the objective of further reduction of child mortality.
\end{abstract}

\section{Subject Areas}

Pediatrics

\section{Keywords}

Child Mortality, Yemen, Poisson Regression, Middle-East, Infant Mortality, Measurement, Brass Indirect Method, NSPMS, Education, Infrastructure

\section{Introduction}

Child mortality is one of the most important indicators of a country's general 
medical and health quality, and subsequently, the country's level of socio-economic development. The effort to reduce mortality in childhood is an obvious duty of each government, but also indicates the will of a country to improve general living standards.

Child mortality rates have declined significantly in the Arab countries over the last two decades: From 83 deaths per 1000 live births in 1990 to 52 deaths per 1000 live births in 2008, that is, a 37 per cent reduction. However, overall, according to UN report in 2003, the Arab region was not on an optimal path for achieving United Nations Millennium Development Goals target of an under-five mortality rate of 28 per 1000 live births by 2015 [1]. The fourth target of the Millennium Development Goals is the reduction by two thirds of the under-five mortality rate, between 1990 and 2015. Figures show that child mortality in Arab region has fallen by only one third in the period. Improvement towards the set target is too slow: in least developed Arab countries, the under-five mortality rate has been reduced by only 15 per cent since 1990 .

Moreover, national averages hide important subnational disparities. For example, in Yemen, the under-five mortality rate among the poor is triple the rate among the rich, and in Egypt, the rate among the poor is two and half times the rate among the rich. Such important disparities can be observed also comparing urban and rural areas.

Yemen is one of the poorest countries in the Middle East and North Africa (MENA) region and has a low Human Development Index (HDI) ranking $168^{\text {th }}$ out of 188 countries in 2016 [2].

In Yemen, Under Five Mortality was reduced from 122 per 1000 live births in 1992 to 78.2 per 1000 live births in 2006. If the same rate of reduction will be sustained, Under Five Mortality is estimated to further drop in the next years, achieving the target of Millennium Development Goals for Yemen.

Infant mortality rate has been reduced from 83 per 1000 live births in 1992 to 69 per 1000 live births in 2006. The 2015 target for infant mortality rate is 27.2 per 1000 live births, which probably was not met. The failure to achieve this goal is mainly due to growth of babies born from mothers that suffer acute malnutrition [3]. Moreover, in Yemen children under five years old suffers from wasting (15.9\%); stunting (49.1\%); and underweight (40.5\%) [4].

Figure 1 shows the trends of mortality for children aged under one year (infant) and for children aged under five years (child).

Figure 1 puts into evidence the fact that reduction of child mortality was more pronounced than the decrease of infant mortality. Moreover, it confirms the fact that Under Five Mortality has been reduced according to the targets of Millennium Development Goals, while the same fact has not happened when we consider infant mortality.

The objective of this paper is to calculate the rate of infant mortality (under one year old) and child mortality (under five years old) and put into evidence some characteristics of households that may influence the rate of child mortality. The database that is used is the Yemen National Social Protection and Monitoring 


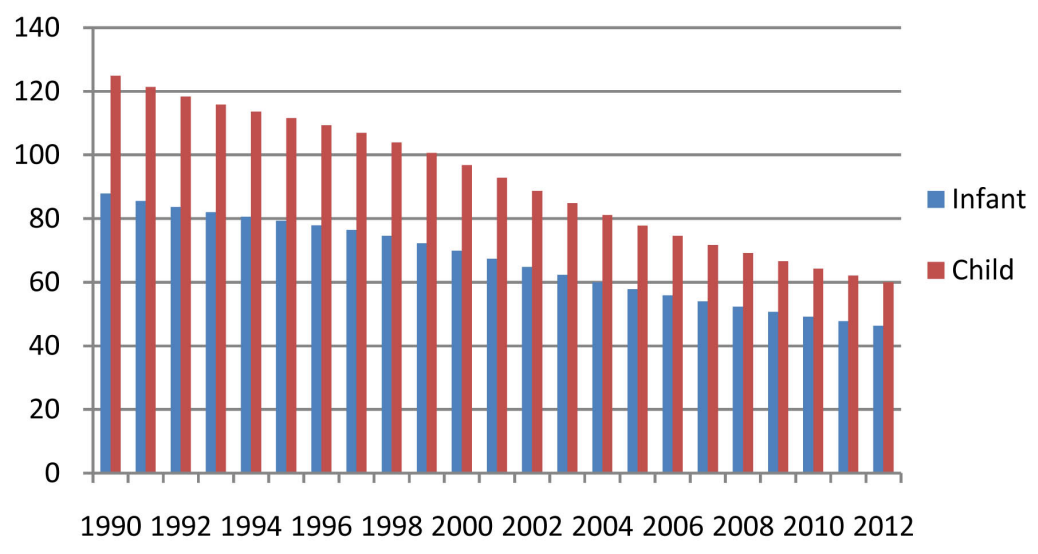

Figure 1. Trends in infant and child mortality rates in Yemen since 1990. Source: UN Inter-agency Group for Child Mortality Estimation database ${ }^{1}$.

Survey (NSPMS).

The paper is divided into five main sections, including this introduction. Section 2 explains in detail the database and its sampling design; in Section 3, infant and child mortality in Yemen are calculated using Brass indirect method; in Section 4, covariates that may affect mortality are introduced and Poisson regression with these covariates is developed and illustrated; finally, Section 5 concludes.

\section{Data Source}

This section describes the Yemen National Social Protection and Monitoring Survey (NSPMS) household sample and the methodology adopted for the survey.

NSPMS surveys resident population in Yemen (excluding non-household communities such as refugees, nomads and internally displaced persons, hotels, dormitories, prisons and hospitals). NSPMS is a longitudinal household survey that will last for 12 months and aims to provide parameter estimates quarterly. The first round of the survey includes data from October to December 2012, the second round from January to March 2013, the third round from April to June 2013 and, finally, the last round from July to September 2013. The present paper utilizes data only from round four.

Yemen is geographically organized into 21 governorates, divided into 333 districts. Districts are subdivided into sub-districts, and each sub-district further subdivided into villages. The Yemeni census data collection system delineates enumeration areas (EAs) within districts. Initial reports specified that each EA should cover approximately 130 households in rural, and between 150 and 180 households in urban areas [5].

The NSPMS sample is selected following a stratified two-phase sampling design. In the first phase, EAs are considered as primary sampling units, and a stratified cluster sampling procedure is employed with unequal selection proba-

${ }^{1}$ UN Inter-agency Group for Child Mortality Estimation database. www.childmortality.org. 
bilities, considering governorates as strata. In the second phase, households are selected from each particular EA by a stratified simple random sampling procedure.

\section{Child Mortality Using Brass Indirect Method}

\subsection{Brass Method Theory}

Indirect methods were created and largely used to calculate mortality in developing and least developed countries, where vital registration systems are not present or exhibit low quality. Indirect methodologies can be utilized when indexes of mortality are not easily obtained or consistent, but other data are available and can be converted into those measures.

Brass [6] [7] was the first demographer to create a method for obtaining estimates of the probability of dying before a determined age converting dead rates of children ever born informed by women in different age groups. That is, the method is based on the fact that survival estimations by cohort, obtained through the proportion of survival children, correspond to an equivalent survival rate by period.

Brass observed that the age pattern of fertility affects the relation between the rates of children dead by age group of mothers and the probability of dying before age $\mathrm{x}[\mathrm{q}(\mathrm{x})]$. This correspondence between mother age group and age $\mathrm{x}$ can be observed in Table 1 .

The correspondences between ages determined by Brass have been widely used by all subsequent analysts. These relations, however, are not exact and depend on the reproductive histories of the particular group of women reporting their births [9]. Brass created multipliers (adjustment factors) with the aim of correcting for the particular reproductive histories of each group of women and transforming the observed values of the proportions of children dead into evaluations of the probability of dying before age $\mathrm{x}[8]$.

\subsection{Results from Indirect Method}

Table 2 shows the values of infant mortality rate (probability of dying before first year of life by 1000), child mortality rate (probability of dying before age of five years by 1000) and life expectancy at birth, calculated through Brass indirect method.

The estimated probability of dying before first year of life is 52.6 by 1000 , which is a figure not far from 46.00 by 1000 estimated by the UN Inter-agency

Table 1. The correspondence relating to age group, age group index $\mathrm{i}$ and age $\mathrm{x}$.

\begin{tabular}{cccccccc}
\hline Age group & $15-19$ & $20-24$ & $25-29$ & $30-34$ & $35-39$ & $40-44$ & $45-49$ \\
\hline i & 1 & 2 & 3 & 4 & 5 & 6 & 7 \\
x & 1 & 2 & 3 & 5 & 10 & 15 & 20 \\
\hline
\end{tabular}

Source: Sarma, Choudhury, 2012 [8]. 
Table 2. Infant mortality rate, child mortality rate and life expectancy at birth.

\begin{tabular}{cccccc}
\hline Indicators & General & Urban & Rural & Read-write & Noread-write \\
\hline $\begin{array}{c}\text { Probability of dying before } \\
\text { first year of life by 1000 }\end{array}$ & 52.6 & 39.9 & 56.1 & 42.0 & 57.9 \\
$\begin{array}{c}\text { Probability of dying before } \\
\text { age of five years by 1000 }\end{array}$ & 78.1 & 59.6 & 83.1 & 62.6 & 85.6 \\
\begin{tabular}{c} 
Life expectancy at birth \\
\hline
\end{tabular} & 63.2 & 63.4 & 63.0 & 65.6 & 62.1 \\
\hline
\end{tabular}

Source: own elaboration from NSPMS.

Group for Child Mortality Estimation in 2012. The same cannot be affirmed for the probability of dying before age of five years, which in this paper is 78.1 by 1000 , while in the estimation of the UN Inter-agency Group for Child Mortality Estimation is 60.00 by 1000 in 2012 .

In 2012, world infant mortality was 35 deaths per 1000 live births [10]. In 2011 the world under-five mortality was 51.55 by 1000 and the under-five mortality rate in developing regions was 57 deaths per 1000 live births [11]. According to these figures, it can be asserted that Yemeni infant mortality is higher compared with world figure and child mortality is elevated if we compare it with world value and with developing regions value.

Passing to observe the differences between urban and rural mortality, rural mortality is considerably higher at both levels of infant and child mortality. Moreover, life expectancies at birth reflect clearly this difference.

Literature explains differences in infant and child mortality between urban and rural zones through household-level and community-level characteristics.

According to the literature about household-level factors, it appears that are important in clarifying rural-urban differences in child mortality. Van de Poel et al. (2007) [12] found that the median rural-urban risk ratio in under-five mortality, in a set of 47 developing countries, can be decreased by $59 \%$ controlling for differences in household wealth. After controlling for a broad range of household socioeconomic and demographic factors, urban child mortality remains significant lower in about one-third of the countries than rural child mortality. This fact may be explained through differences in community-level characteristics, such as availability of health care services, which are hypothetically significant explicators of the rural-urban disparity in infant mortality. Sastry $(1996,1997)$ [13] [14] puts into evidence the importance of community-level factors in the explanation of the rural-urban infant mortality discrepancy in Brazil. The paper of Heaton and Forste (2003) [15] concluded that the restricted supply of health care is partly accountable for the lower survival rates of children born in the rural Bolivia. Van de Poel et al. (2009) [16] developed a decomposition analysis to study rural-urban differences in infant mortality in six Central and West sub-Saharan African countries. In that paper, rural-urban differences in infant mortality are explained by variances in the distributions of factors that determine mortality and not by differences in the effects of those 
determinants between rural and urban locations. Another important conclusion of the paper is the evidence that rural-urban differences in household-level factors, which explain two-thirds of the gap, are much more significant than those in community-level factors, which explain less than one-quarter.

Table 2 provides also information about infant and child mortality for children whose mothers are literate or illiterate. We can observe also in this case that the difference in mortalities is significant among the two categories. Children whose mother can read and write have less mortality rates before both first year and fifth year of life. Additionally, life expectancies at birth confirm visibly this difference.

Literature about effects of mother's education on infant and child mortality supports the results of this paper. For instance, UNESCO (2011) [17] evidenced the fact that each extra year of a mother's schooling reduces the probability of infant mortality by $5 \%$ to $10 \%$ globally.

Some ways through which education improves the rates of infant and child mortality are the propensity of mothers to seek modern birth options, the availability of more and better trained birth attendants, a low rate of risky teenage births, and a reduced number of children born from each woman. For example, in Burkina Faso, mothers with secondary education are twice as likely to give birth in health facilities as those with no education. Moreover, children of educated mothers are more likely to be vaccinated and less likely to be stunted because of malnourishment. In Indonesia, child vaccination rates are 19\% when mothers have no education. This increases to $68 \%$ when mothers have at least a secondary school education [17].

Furthermore, the researches of UNESCO (2011) [17] supported that child whose mother can read is $50 \%$ more likely to live past age 5 and that, in sub-Saharan Africa, approximately 1.8 million children's lives could be saved if their mothers had at least secondary education.

Gakidou et al. (2010) [18] found that, over the past four decades, the global increase in women's education has prevented more than 4 million child deaths.

\section{Poisson Regression with Covariates}

\subsection{Poisson Regression Theory}

Poisson regression is a type of nonlinear estimation. The Poisson distribution is utilized for a dependent variable y that takes only nonnegative integer values or ratios. So, it can be used to model the number of occurrences of an event or the rate at which an event happens, such as number of cases of a disease and mortality rate in a country.

The Poisson density, or more formally the Poisson probability mass function, with rate parameter $\lambda$, is

$$
f(y \mid \lambda)=\mathrm{e}^{-\lambda} \lambda^{y} / y !, y=0,1,2, \cdots
$$

The first two moments are: 


$$
\mathrm{E}[y]=\lambda \text { and } \mathrm{V}[y]=\lambda
$$

The parameter $\lambda$ varies across individuals according to a specific function of regressor vector $x$ and parameter vector $\beta$. The usual Poisson specification is

$$
\lambda=\exp \left(x^{\prime} \beta\right)
$$

The log likelihood function is the join density, that is, the product $\prod_{i} f\left(y_{i} \mid x_{i}, \beta\right)$ of individual densities conditioned on the regressors:

$$
f(y \mid \boldsymbol{x}, \beta)=\mathrm{e}^{-\exp \left(x^{\prime} \beta\right)} \exp \left(\boldsymbol{x}^{\prime} \beta\right)^{y} / y !
$$

The log-likelihood function is then the logaritm of a product, which is equivalent to the sum of logaritms:

$$
\ln f\left(y_{i} \mid \boldsymbol{x}_{i}, \beta\right)=-\exp \left(\boldsymbol{x}_{i}^{\prime} \beta\right)+y_{i} \boldsymbol{x}_{i}^{\prime} \beta-\ln y_{i} !
$$

Finally, the Poisson maximum likelihood estimation $\beta_{p}$ is the solution to the first-order condition:

$$
\left.\frac{1}{N} \sum_{i=1}^{N}\left(y_{i}-\exp \left(\boldsymbol{x}_{i}^{\prime} \beta\right)\right) \boldsymbol{x}_{i}\right|_{\hat{\beta}}=\mathbf{0}
$$

[19].

In the case of nonlinear models, the coefficient $\beta$ cannot be interpreted as the effect of a one-unit change in regressors on the conditional mean, like in the case of linear models. For nonlinear models the interpretation is different, that is, the effect of a one-unit change in regressors on the conditional mean is igual, in this case, to $\beta \exp \left(x^{\prime} \beta\right)$ [20].

In the Poisson regression, the result of interest is known as the incidence rate-that is, $\lambda$ estimated. The usual way to compare two situations, then, is the incidence rate ratio (or IRR). For e.g. a binary covariate $X_{D}$, we can see the IRR as the ratio:

$$
\frac{\hat{\lambda} \mid X_{D}=1}{\hat{\lambda} \mid X_{D}=0}=\frac{\exp \left(\hat{\beta}_{0}+\bar{X} \hat{\beta}+\left(X_{D}=1\right) \hat{\beta}_{X_{D}}\right)}{\exp \left(\hat{\beta}_{0}+\bar{X} \hat{\beta}+\left(X_{D}=0\right) \hat{\beta}_{X_{D}}\right)}=\exp \left(\hat{\beta}_{X_{D}}\right)
$$

In the same way, we can see the relative change in the incidence rate for a one-unit change in any given variable $X_{k}$ by a simply exponentiation of its estimated coefficient $\beta_{k}$.

\subsection{Covariates}

The covariates utilized in the Poisson regression are relative to mother's education (basic_secondary), the quantity of water available in the family (water), the presence of electricity from public grid in the household (electricity), economic shock experienced by the household (no_econ_shock), the distance to nearest medical facility (time_medical) and prenatal consultations (prenatal), whose detailed descriptions can be found in Table 3.

Basic_secondary is a binary variable that shows if mother has attained basic ( 9 years of schooling), or secondary education or more (12 years of schooling or 
Table 3. Description of covariates.

\begin{tabular}{|c|c|}
\hline Variable & Description \\
\hline basic_secondary & $\begin{array}{l}1=\text { mother has basic education ( } 9 \text { years of schooling) } \\
\text { or secondary education ( } 12 \text { years of schooling or more) } \\
0=\text { none and non-standard education }\end{array}$ \\
\hline water & $\begin{array}{l}1=\text { liters of water per capita per day in the household } \geq 100 \\
0=\text { liters of water per capita per day in the household }<100\end{array}$ \\
\hline electricity & $\begin{array}{l}1=\text { the main sourse of light in the house is from the public grid } \\
0=\text { the main sourse of light in the house is not from the public grid }\end{array}$ \\
\hline no_econ_shock & $\begin{array}{l}1=\text { the household did not experience any economic shock } \\
\text { over the past three months } \\
0=\text { the household experienced some economic shock } \\
\text { over the past three months }\end{array}$ \\
\hline time_medical & Distance of household to nearest medical facility in minutes \\
\hline prenatal & $\begin{array}{l}1=\text { at least } 1 \text { prenatal consultation with a skilled attendant } \\
\text { in the last pregnancy } \\
0=\text { no prenatal consultation with a skilled attendant in the last pregnancy }\end{array}$ \\
\hline
\end{tabular}

Source: own elaboration.

more) or not. In this paper, this variable is compared with other binary variables: none (without any level of schooling) and non-standard: Quran \& literacy.

Beyond the explication provided in Section 3.2, mother's education is inversely associated with child probability of death due also to larger efficiency of the woman in household production, tastes, or genetics. However, mother's level of schooling may represent also market efficiency and, so, larger earnings in the work, which, in turn, lead to a reduction of mortality [21]. Considering the data of NSPMS about all women, it can be observed that the category of schooling more present is basic with a percentage of 49.93 . The second larger subgroup relative to schooling is none with a percentage of 27.02 , while the subgroup secondary represents 20.62 per cent of all women. Finally, the percentage of women that have achieved a non-standard education is very low (2.44\%).

Water is a variable that identifies the quantity of water (liters) from any origin per capita per day available in the household. It is a dummy variable that shows whether the quantity of water per capita per day is more than 100 liters. The World Health Organization (WHO) [22] sets the minimum per capita consumption of100liters of water-enough for a person to basic hydration, have a proper hygiene and prepare food.

The quantity of water used in households is hugely relevant for Yemen, since it is one of the most water-scarce countries in the world [23].

Particular population groups have specific hydration requirements, including young children, pregnant or lactating women, the elderly and the terminally ill. For example, the losses of water from the bodies of small children are significantly greater than for adults, $15 \%$ of water per day as opposed to $4 \%$.

The necessity of domestic water for ensuring basic health is larger than the minimum required for consumption (drinking and cooking). Additional quanti- 
ties are essential for maintaining food and personal hygiene through hand and food washing, bathing and laundry. It is proven that a lack of sufficient quantity of domestic water causes poor hygiene [24].

The diseases related to poor hygiene include diarrhoeal and other diseases transmitted through the faecal-oral route; skin and eye diseases, in particular trachoma and diseases related to infestations, for instance louse and tick-borne typhus [24] [25].

Water is also indispensable for preparing food. Herbert [26] noted that the quantity of cooking water available may be an important element for diarrhoea incidence in children over 3 years of age.

Electricity is a binary variable that indicates whether the main source of light in the house is from the public grid. Availability of electricity in the households is also considered in this study since adequate supply of energy is indispensable for correct cooking of food, boiling water, and sterilizing stored food and utensils. Energy is also required for refrigeration to preserve food, preventing in this way diarrheal diseases resulting from bacterial presence in stored food. Researches reveal that households with electricity experience significant lower child mortality compared to those without it [27].

The next covariate, no_econ_shock, specifies wheter the household experienced some economic shock over the three months previous the survey. The empirical literature from developing and least developed countries suggests that child health aggravates when there are negative income or wealth shocks, for example, we can cite Bhalotra (2008) [28] on India. Economic shocks on households have income and substitution effects on child health. The income effect may lead households to spend a smaller amount of money on health-goods, including nutritious foods and health care, especially if households are credit-constrained.

Time_medical is a variable that evidences the distance of household to nearest medical facility in minutes. It has been documented that primary health care drops with growing distance or travel time to a medical facility. Thus, time needed to reach a health facility is a main aspect in determining the utilization of health facilities in rural areas of developing and least developed countries. Several studies have documented the relationship between distance or travel time and health outcomes. Researches about Zambia [29] and Burkina Faso [30] provided proof that a large travel time or distance to a health facility was related to a higher child mortality risk. Similarly, in Uganda it was evidenced that distance to a medical facility affects child mortality and the effect was more evident in children that have mothers with a low level of education [30].

The last variable, prenatal, evidences whether the woman had at least 1 prenatal consultation with a skilled attendant in the last pregnancy. Prenatal care is an important public health intervention directed to improve birth outcomes. However, there is no consensus in the literature about its effect on child health. Researches for developing countries have been limited because of the absence of consistent data on child health and prenatal, but these show inconsistent results 
as well. For instance, Guilkey et al. (1989) [32] found both positive and negative effects on birth weight depending on geographical area, type of prenatal provider and medical facility where the care was provided.

\subsection{Results from Poisson Regression}

The dependent variable used in Poisson regression is the rate of survival children for women aged between 30 and 35 years over all children that were born from these women. In practice, the count variable is the number of children alive for women aged between 30 and 35 years, while the exposure variable is the total number of children that these women have given birth during their lives. Remembering the Brass method, we consider only women aged between 30 and 35 years because we want to observe the correlation between covariates and survival rate before age of five years.

The results of Poisson regression in format of incidence-rate ratios (IRR) using round 4 data are showed in Table 4.

From the results, showed in Table 4, it can be observed that almost all covariates have statistical significance, with exception of prenatal; however the level of significance is different. The most statistically significant are water and no_econ_shock, with a level of significance of 1 percent, while the variables that exhibit a low level of significance are time_medical at 5 per cent, and basic_secondary and electricity at 10 per cent.

The first variable, basic_secondary, appears to have a positive effect on survival rate of children before age of five years. Poisson regression suggests that mothers that attained basic or secondary level of education or more may incur a reduced rate of mortality of their children until the age of five.

Thus, according to Poisson regression, mothers with secondary education or more have an estimate survival rate of their children 1.068 times the survival rate of mothers of other categories (none and non-standard).

The covariate water seems to have a positive correlation with the dependent variable. The positive correlation of available quantity of water with the dependent variable can be seen through the value of the incidence-rate ratio, which

Table 4. Poisson regression results.

\begin{tabular}{cc}
\hline Variable & IRR \\
\hline basic_secondary & $1.068^{*}$ \\
water & $1.077^{* * *}$ \\
electricity & $1.041^{\star}$ \\
no_econ_shock & $1.125^{* * *}$ \\
time_medical & $1.000^{* *}$ \\
prenatal & 0.955 \\
constant & $0.697^{* * *}$
\end{tabular}

Source: own elaboration from NSPMS. Significance levels: ${ }^{*} 10$ percent, ${ }^{* *} 5$ percent, ${ }^{* * *} 1$ percent. 
indicates that mothers with more than 100 liters of water available per day have an estimate survival rate of their children 1.077 times the survival rate of children of other mothers.

Also, electricity has a positive correlation with the survival rate of children before age of five years. In this case the incidence-rate ratio is 1.041, evidencing that the presence of electricity may have a role in reducing child mortality.

The successive covariate, no_econ_shock, has a positive effect on child survival, as showed by an incidence-rate ratio larger than one. That is, mothers living in a household that did not experience any economic shock over the past three months have an estimate survival rate of their children 1.125 times the survival rate of other mothers.

The two successive variables seem to have no effect on child mortality: time_medical has an incidence-rate ratio very close to one, showing basically no effect, while prenatal is statistically insignificant.

Finally, we have to put into evidence the result about the constant. it is statistically significant at a level of $1 \%$ and the suppose effect on dependent variable is negative. The constant is the Poisson regression estimate when all variables in the model are evaluated at zero. Specifically, this is the estimate when mothers have no education, or non-standard, the liters of water per capita per day in the household are lower than 100, the main sourse of light in the house is not from the public grid, the household experienced some economic shock, the household is close to medical facility and mothers have no prenatal consultation with a skilled attendant in the last pregnancy. The negative correlation of the constant with the survival rate of children before age of five years agrees with the expected results.

In conclusion, all covariates, with exception of time_medical and prenatal, have an incidence-rate ratio statistically significant and a positive value as expected.

A further analysis can be developed using post estimation tools.

Through post estimation analysis, the survival rate before age of five years relative to each covariate can be found, according to the regression model. Given the survival rate, the probability of dying before age of five years by 1000 can be easily calculated.

Table 5 shows the values of the probabilities of dying before age of five years by 1000 and their relative intervals at a level of confidence of $95 \%$ calculated through post estimation analysis.

It can be observed that the general probability of dying before age of five years is slightly higher than the probability calculated through indirect method. In the case of post estimation analysis the general child mortality is 60.17 by 1000 , while in the case of indirect method is 56.40 by 1000 .

Moreover, this analysis puts into evidence more clearly the importance of achieving, at least, basic or secondary education: children from mothers with this level of education may suffer less than half of the mortality of children from mothers that have lower levels of education. 
Table 5. Results from post estimation analysis.

\begin{tabular}{cccc}
\hline $\begin{array}{c}\text { Probability of dying before } \\
\text { age of five years by 1000 }\end{array}$ & Value & $\begin{array}{c}\text { 95\% CI } \\
\text { Lower }\end{array}$ & $\begin{array}{c}\text { 95\% CI } \\
\text { Upper }\end{array}$ \\
\hline General & 60.17 & 51.19 & 69.15 \\
basic_secondary (=1) & 28.61 & 13.18 & 44.05 \\
basic_secondary (=0) & 73.00 & 62.76 & 83.24 \\
water (=1) & 32.91 & 22.44 & 43.38 \\
water (=0) & 95.80 & 84.34 & 107.26 \\
electricity (=1) & 49.83 & 37.22 & 62.44 \\
electricity (=0) & 71.65 & 59.06 & 84.24 \\
no_econ_shock $(=1)$ & 47.62 & 39.64 & 55.61 \\
no_econ_shock $(=0)$ & 141.99 & 117.00 & 166.98 \\
\hline
\end{tabular}

Source: own elaboration from NSPMS.

Furthermore, post estimation analysis supports the probable effect of the presence of water in household. The value of the probability of dying before age of five years is widely lower for children living in water secure household than for children from household without water security.

In the case of electricity, we can observe that children living in households with public grid have a lower probability of dying before age of five years than children living in household with other sources of electricity or without electricity.

Finally, the supposed effect of an economic shock on child mortality is very large: the figure of the probability of dying before age of five years in the case of economic shock is nearly three times the probability in the case of no economic shock.

\section{Conclusions}

According to the results of this analysis, infant and child mortality rates are elevated in Yemen. Yemeni infant and child mortality rates are high if we compare them to figures of the world and developing countries.

Moreover, the values about infant and child mortality achieved through Brass indirect method are near to the values from other estimations available in the literature. Moreover, the figure of child mortality obtained through Poisson post estimation analysis agrees with other analysis.

With regard to Poisson regression, the covariates utilized in this analysis are almost all statistically significant, but at different level of significance. Poisson regression puts into evidence the importance of mother education in reducing child mortality. Likewise, the quantity of water available in the household may be considered a relevant characteristic, because appears improving survival rates of children until the age of five and its level of statistical significance is $1 \%$. Another important conclusion is about the supposed effect of the economic sit- 
uation of the household, which appears to increase child mortality. The electricity in household is another important factor that may explain child mortality, but with a lower level of significance.

We can conclude affirming that Yemen needs to increase the access to schools of population, particularly of girls, and improve the infrastructure of the country, mainly water and electricity supply, with the objective of further reduction of child mortality.

\section{Acknowledgements}

The author is greatly grateful to the International Policy Centre for Inclusive Growth of UNDP for the provision of the database and useful comments on the paper.

\section{Conflicts of Interest}

The author declares no conflicts of interest regarding the publication of this paper.

\section{References}

[1] UN (2013) The Arab Millennium Development Goals Report. United Nations ESCWA, Beirut.

[2] UNDP (2016) Human Development Report 2016. United Nations Development Programme, New York.

[3] WFP (2012) The State of Food Security and Nutrition in Yemen-Comprehensive Food Security Survey. Sana'a, World Food Programme.

[4] UNDP (2010) Yemen-The Second National Millennium Development Goals Report. United Nations Development Programme.

[5] Vieira, M.D.T. and Ferraz, C. (2013) The Technical Report on the Sampling Design for the Yemen National Social Protection and Monitoring Survey. Updated Version. Brasília, International Policy Centre for Inclusive Growth.

[6] Brass, W. (1964) Uses of Census and Survey Data for Estimation of Vital Rates, (E/CN. 14/CAS.4/V57). African Seminar on Vital Statistics. Addis Ababa, 14-19 December 1964.

[7] Brass, W. (1975) Methods for Estimating Fertility and Mortality from Limited and Defective Data. Occasional Publication. Inter-national Program of Laboratories for Population Statistics, University of North Carolina at Chapel Hill, Chapel Hill.

[8] Sarma, R. and Choudhury, L. (2012) A Critique of Infant Mortality Estimates in India. Journal of Data Science, 10, 563-578.

[9] Preston, S.H., Heuveline, P. and Guillot, M. (2003) Indirect Estimation Methods. In: Demography, Measuring and Modelling Population Processes, Blackwell Publishers Limited, United Kingdom, 224-255.

[10] WHO, World Health Organization (2013) World Health Statistics 2013. Geneva.

[11] UNICEF (2012) Levels and Trends in Child Mortality-Report 2012. United Nations Children's Fund.

[12] Van de Poel, E., O'donnell, O. and Van Doorslaer, E. (2007) Are Urban Children Really Healthier? Evidence from 47 Developing Countries. Social Science \& Medi- 
cine, 65, 1986-2003. https://doi.org/10.1016/j.socscimed.2007.06.032

[13] Sastry, N. (1996) Community Characteristics, Individual and Household Attributes, and Child Survival in Brazil. Demography, 33, 211-229. https://doi.org/10.2307/2061873

[14] Sastry, N. (1997) What Explains Rural-Urban Differentials in Child Mortality in Brazil? Social Science \& Medicine, 44, 989-1002. https://doi.org/10.1016/S0277-9536(96)00224-9

[15] Heaton, T.B. and Forste, R. (2003) Rural-Urban Differences in Child Growth and Survival in Bolivia. Rural Sociology, 68, 410-433. https://doi.org/10.1111/j.1549-0831.2003.tb00144.x

[16] Van de Poel, E., O’Donnell, O. and Van Doorslaer, E. (2009) What Explains the Rural-Urban Gap in Infant Mortality: Household or Community Characteristics? Demography, 46, 827-850.

[17] UNESCO (2011) Education Counts. Towards the Millennium Development Goals. Education for All Global Monitoring Report. United Nations Educational, Scientific and Cultural Organization, Paris.

[18] Gakidou, E., Cowling, K., Lozano, R. and Murray, C.J.L. (2010) Increased Educational Attainment and Its Effect on Child Mortality in 175 Countries between 1970 and 2009: A Systematic Analysis. The Lancet, 376, 959-974. https://doi.org/10.1016/S0140-6736(10)61257-3

[19] Cameron, A.C. and Trivedi, P.K. (2005) Microeconometrics: Methods and Applications. Cambridge University Press, Cambridge. https://doi.org/10.1017/CBO9780511811241

[20] Cameron, A.C. and Trivedi, P.K. (2001) Essentials of Count Data Regression. In: Baltagi, B.H., Ed., A Companion to Theoretical Econometrics, Blackwell, Oxford, 331-348.

[21] Wolfe, B.L. and Behrman, J.R. (1982) Determinants of Child Mortality, Health and Nutrition in a Developing Country. Journal of Development Economics, 11, 163-193.

[22] WHO, World Health Organization (2003) Total Dissolved Solids in Drinking-Water. Background Document for Development of WHO Guidelines for Drinking-Water Quality. WHO, Geneva.

[23] Klasen, S., Lechtenfeld, T., Meier, K. and Rieckmann, J. (2011) Impact Evaluation Report: Water Supply and Sanitation in Provincial Towns in Yemen. Courant Research Centre PEG, No. 102.

[24] Cairncross, S. and Feachem, R. (1993) Environmental Health Engineering in the Tropics: An Introductory Text. 2nd Edition, John Wiley and Sons, Chichester.

[25] Bradley, D. (1977) Health Aspects of Water Supplies in Tropical Countries. In: Feachem, R., McGarry, M. and Mara, D., Eds., Water, Wastes and Health in Hot Climates, John Wiley and Sons, Chichester, 3-17.

[26] Herbert, J. (1985) Effects of Components of Sanitation on Nutritional Status: Findings from South Indian Settlements. International Journal of Epidemiology, 14, 143-151. https://doi.org/10.1093/ije/14.1.143

[27] Gayawan, E. and Turra, C.M. (2012) Fatal Years: Analyzing Determinants of Child Mortality in Two Developing Countries from Retrospective Reports of Mothers. XVIII Encontro Nacional de Estudos Populacionais, ABEP, Cedeplar/Face/UFMG.

[28] Bhalotra, S. (2008) Fatal Fluctuations? Cyclicality in Infant Mortality in India. Journal of Development Economics, 93, 7-19. 
https://doi.org/10.1016/j.jdeveco.2009.03.006

[29] Kapungwe, A. (2005) Quality of Child Health Care and Under-Five-Mortality in Zambia: A Case Study of Two Districts in Luapula Province. Demographic Research, 12, 301-322. https://doi.org/10.4054/DemRes.2005.12.12

[30] Schoeps, A., Gabrysch, S., Niamba, L., Sié, A. and Becher, H. (2011) The Effect of Distance to Health-Care Facilities on Childhood Mortality in Rural Burkina Faso. American Journal of Epidemiology, 173, 492-498. https://doi.org/10.1093/aje/kwq386

[31] Katende, C. (2003) The Impact of Access to Health Services on Infant and Child Mortality in Rural Uganda. Population Studies, 9.

[32] Guilkey, D.K., Popkin, B.M., Akin, J.S. and Wong, E. (1989) Prenatal Care and Pregnancy Outcome in the Philippines. Journal of Development Economics, 30, 241-272. https://doi.org/10.1016/0304-3878(89)90003-5 